Derleme / Review

\title{
Kardiyovasküler risk faktörleri
}

\section{Cardiovascular risk factors}

\section{Okan Gülel}

Ondokuz Mayıs Üniversitesi, Tıp Fakültesi, Kardiyoloji Anabilim Dalı, Samsun, Türkiye

\begin{tabular}{|c|c|}
\hline MAKALE BİLGÍLERİ & ÖZET \\
\hline Makale geçmişi & Aterosklerotik kardiyovasküler hastalıklar en önde gelen ölüm sebepleri arasında yer al- \\
\hline Geliş tarihi $\quad: 30 / 06 / 2011$ & maktadır. Ateroskleroz sürecinde kardiyovasküler risk faktörleri önemli rol oynamakta- \\
\hline$: 05 / 07 / 2011$ & $\begin{array}{l}\text { dır. Risk faktörleri azaldıkça hem kardiyovasküler olaylar hem de tüm sebeplerden mor- } \\
\text { talite azalmaktadır. Bu yazıda, geleneksel ve yeni kardiyovasküler risk faktörleri güncel }\end{array}$ \\
\hline Yazışma Adresi: & $\begin{array}{l}\text { literatür bilgisi 1ş1ğında gözden geçirilmiştir. } \\
\text { J. Exp. Clin. Med., 2012; 29:S107-S116 }\end{array}$ \\
\hline
\end{tabular}

Okan Gülel

Ondokuz Mayıs Üniversitesi,

Tıp Fakültesi, Kardiyoloji Anabilim Dalı,

Samsun, Türkiye

e-posta: okangulel@hotmail.com

\begin{abstract}
Atherosclerotic cardiovascular diseases are among the leading causes of death. Cardiovascular risk factors play an important role in the atherosclerotic process. As risk factors decrease, both cardiovascular events and all-cause mortality decrease. In this article, conventional and new risk factors were reviewed in the light of current literatures.

J. Exp. Clin. Med., 2012; 29: S107-S116
\end{abstract}

Anahtar Kelimeler:

Ateroskleroz

Kardiyovasküler

Risk faktörleri

Mortalite

Komplikasyon

\section{Keywords:}

Atherosclerosis

Cardiovascular

Risk factors

Mortality

Complication

\section{Giriş}

Aterosklerotik kardiyovasküler hastalıklar en önde gelen ölüm sebepleri arasında yer almaktadır (Allender ve ark., 2008). Ateroskleroz çocukluk yıllarında başlar, uzun bir asemptomatik dönemden sonra klinik sonuçları görülür (McMahan ve ark., 2007). Bu süreçte kardiyovasküler risk faktörleri önemli rol oynamaktadır. Tüm koroner ölümlerin yaklaşık yarısının daha önce teşhis edilmemiş veya semptomu olmayan hastalarda olduğu gerçeği kardiyovasküler risk değerlendirmesinin ne kadar önemli olduğunu göstermektedir (Ni ve ark., 2009). Kardiyovasküler risk faktörleri azaldıkça hem kardiyovasküler olaylar hem de tüm sebeplerden mortalite azalmaktadır. Üstelik risk faktörlerini azaltmaya yönelik girişimler kardiyovasküler olaylarda azalmaya yol açabilmektedir (Rothwell ve ark., 2004). Bu nedenle risk faktörlerinin azaltılması hem primer korunmada hem de aterosklerozun akut ve kronik komplikasyonlarının yönetiminde mutlaka sağlanmalıdır.

\section{Değiştirilemeyen risk faktörleri}

\section{Yaş ve cinsiyet}

Kardiyovasküler hastalıklar yaş ilerledikçe (erkeklerde $\geq 45$ yaş, kadınlarda $\geq 55$ yaş) artış gösterir. Kalp hastalığı ve felç istatistiklerine göre erkeklerin \%47'si, kadınların \%53'ü aterosklerotik kardiyovasküler hastalıklardan ölmektedir (Thom ve ark., 2006). Genç erkeklerde koroner arter hastal1ğ1 morbidite ve mortalitesi kadınlardan 4-5 kat fazlayken ileri yaşlarda bu fark azalmaktadır. Benzer şekilde 65 yaş altında 
felç riski erkeklerde 2 kat fazladır (Rosengren ve ark., 2009). Kadınlarda menapozla beraber östrojen seviyeleri düşmekte, koroner kalp hastalığı insidansında belirgin bir artış olmaktadır. Premenapozal dönemde ise koroner kalp hastalığı nadirdir. Östrojen HDL kolesterolü arttırır, LDL kolesterol ve lipoprotein(a) seviyeleri ile küçük yoğun LDL partiküllerini azaltır. Koroner vazodilatasyona sebep olur, anjiyogenezi tetikler, antioksidandır, intimal hiperplaziyi ve düz kas hücre göçünü önler. Koagülasyon parametreleri ve fibrinolitik sistem üzerine olumlu etkileri vardır (Maron ve ark., 2008).

\section{Pozitif aile hikayesi}

Birinci derece akrabalarda prematür ateroskleroz öyküsü (erkeklerde $<55$ yaş, kadınlarda $<65$ yaş) gelecekteki kardiyovasküler olaylar için önemli bir öngörücüdür. Framingham Offspring Çalışması'na dahil edilen hastalarla yapılan bir analizde ebeveynlerin birindeki prematür kardiyovasküler hastalık öyküsü kardiyovasküler riski 2,3-2,6 kat arttırmaktaydı (Lloyd-Jones ve ark., 2004). Hatta prematür olmayan koroner kalp hastalığı aile hikayesi de koroner kalp hastalığ1 riskini 1,73 kat arttırmaktadır (Hawe ve ark., 2003). Prematür ateroskleroz öyküsü ne kadar fazla yakın akrabada mevcutsa, ne kadar erken yaşta ortaya çıkmışsa ve ne kadar genetik olarak yakın akrabada oluşmuşsa risk de o ölçüde artmaktadır (Rissanen, 1979). Bu nedenlerden dolayı American College of Cardiology Foundation/American Heart Association (ACCF/AHA), asemptomatik hastalarda risk değerlendirmesi için aile hikayesinin öğrenilmesini önermektedir (Sınıf I, Kanıt Düzeyi B) (Greenland ve ark., 2010). Ancak ateroskleroza genetik yatkınlık için günlük klinik pratikte kullanımı kabul edilen herhangi bir tarama testi bulunmamaktadır. ACCF/ AHA, asemptomatik hastalarda risk değerlendirmesi için genetik tarama yapılmasını önermemektedir (Sınıf III, Kanıt Düzeyi B) (Greenland ve ark., 2010).

\section{Değiştirilebilen risk faktörleri}

\section{Sigara}

Sigara kullanımı özellikle genç bireylerde ve kadınlarda artış göstermektedir. Sigara ile ilişkili ölümlerin yaklaşık \%35-40'ını iskemik kalp hastalığ 1 oluşturmaktadır (Ridker ve Libby, 2008). Sigara gibi puro ve pipo içimi de koroner kalp hastalığı riskini arttırmaktadır. Filtrelerin riski azalttığ1 gösterilememiştir (Maron ve ark., 2008). Pasif içicilik de koroner dolaşımda endotel disfonksiyonuna neden olarak sigara kullanmayanlara kıyasla koroner kalp hastalığı riskini 1,25 kat arttırmaktadır (He ve ark., 1999). Tüketilen sigara miktarı arttıkça risk de artmaktadır. Yaş, cinsiyet ve ırktan bağımsız olarak sigara ile koroner kalp hastalığı arasında güçlü bir doz-risk ilişkisi saptanmıştır (U.S. Department of Health and Human Services, 2004). Sigara sadece miyokart enfarktüsü riskini değil ani ölüm, periferik arter hastalığı, felç ve aort anevrizması riskini de arttırmaktadır (Ridker ve Libby, 2008).

Sigaranın bu negatif etkilerinin patofizyolojik mekanizmaları nelerdir?

Sigara kan basincinda, sempatik aktivitede ve miyokart oksijen sunumunda olumsuz etkilere sebep olmaktadır. Platelet agregasyonunu ve monositlerin endotele yapışmasını arttırır, endotel kökenli fibrinolitik ve antitrombotik faktörlerde olumsuz etkilere sebep olur (Ridker ve Libby, 2008). Endo- teldeki nitrik oksit sentezinde bozulmaya yol açarak koroner arter vazodilatasyonunu olumsuz etkiler, vazoreaktiviteyi arttırır (Barua ve ark., 2003). İskemi ve malign aritmi eşiğini düşürür ve koroner spazmı tetikler. Karbonmonoksit ve nikotin ile endotel hasarına sebep olur. LDL kolesterolün oksidasyonunu tetikler, HDL kolesterol seviyesini düşürür (Maron ve ark., 2008). C-reaktif protein, fibrinojen ve homosistein seviyelerini arttırır (Bazzano ve ark., 2003). Sigaranın bu olumsuz etkilerini azaltmanın en iyi yolu sigaranın bırakılmasıdır. Sigaranın birakılması koroner kalp hastalarında mortaliteyi \%36 azaltır (Critchley ve Capewell, 2003). Risk düzeyi, sigaranın bırakılmasından sonraki ilk bir yıl içerisinde sigara içmeyen birey kadar azalır (Gordon ve ark., 1974). Sigaranın azaltılması ise kardiyovasküler hastalık ve mortalite riskinde azalma yapmamaktadır (Godtfredsen ve ark., 2002).

\section{Hipertansiyon}

Framingham Kalp Çalışması'na dahil edilen hastalarla yapılan bir analizde optimal kan basıncına kıyasla yükseknormal kan basıncı değerleri (130-139 mmHg aralığındaki sistolik kan basıncı, 85-89 mmHg aralığındaki diyastolik kan basıncı veya her ikisi) kardiyovasküler hastalık riskini kadınlarda 2,5 kat, erkeklerde 1,6 kat arttırmaktaydı (Vasan ve ark., 2001). Sistolik ve diyastolik kan basınçları arasındaki fark olarak tanımlanan nabız basıncı da bağımsız olarak kardiyovasküler olaylarda öngörücüdür. Nabız basıncındaki her 16 mmHg artış, konjestif kalp yetersizliği riskinde \%55 artışa sebep olmaktadır (Haider ve ark., 2003). Antihipertansif ilaçlarla yapılan çalışmaların meta-analizi, tedavi ile kan basıncındaki düşmenin felç riskinde $\% 38$, koroner kalp hastalığ riskinde $\% 16$, vasküler mortalitede $\% 21$ azalma sağladığını göstermiştir (Collins ve MacMahon, 1994).

\section{Hipertansiyonun bu negatif etkilerinin patofizyolojik mekanizmaları nelerdir? \\ Hipertansiyon endotel disfonksiyonuna sebep olur. Ok-} sidatif stresi, lipoproteinlerin endotel geçirgenliğini, lökositlerin endotele bağlanmasını, miyokart duvar gerilimini ve oksijen ihtiyacını arttırır (Maron ve ark., 2008). Hastaların çoğunda ilave olarak insülin direnci, dislipidemi, sol ventrikül hipertrofisi ve obezite gibi ek risk faktörleri bulunmaktadır (Kannel, 1996). Hipertansiyonun sebep olduğu ve elektrokardiyografi veya ekokardiyografi ile saptanabilen sol ventrikül hipertrofisi ventrikül esnekliğini ve koroner rezervi azaltmakta, sistolik fonksiyonları bozmakta ve ventriküler ektopiyi tetiklemektedir (Maron ve ark., 2008). Framingham Kalp Çalışması'na dahil edilen hastalarla yapılan bir analiz, sol ventrikül kitle indeksinin her $50 \mathrm{~g} / \mathrm{m}^{2}$ artışında kan basıncı düzeyinden bağımsız olarak kardiyovasküler hastalık riskinin erkeklerde 1,49 kat, kadınlarda 1,57 kat arttığını göstermiştir (Levy ve ark., 1990). Hipertansif popülasyonda konsantrik hipertrofinin, eksantrik hipertrofiden daha riskli olduğu bildirilmektedir (Greenland ve ark., 2010). HOPE çalışmasında, ramipril ile hem elektrokardiyografik sol ventrikül hipertrofisinin oluşmasının azaldığı hem de sol ventrikül hipertrofisinin gerilediği ve bunun ölüm, miyokart enfarktüsü, felç ve konjestif kalp yetersizliği riskini azalttığı gösterilmiştir (Mathew ve ark., 2001).

JNC 7 (Seventh Report of the Joint National Committee on Prevention, Detection, Evaluation, and Treatment of High Blood Pressure), kan basıncının kontrol altına alınmasında 
ilaç-dışı tedavi yaklaşımlarından kilo verme, sodyum kısitlaması ile beraber DASH diyeti, potasyumdan zengin g1daların tüketilmesi ve fiziksel aktiviteye vurgu yapmaktadır (Chobanian ve ark., 2003). Ancak hastaların çoğu hedef kan basıncına ulaşmak için farmakolojik tedaviye ihtiyaç duymaktadır. Anti-hipertansif ilaç gruplarının etkinliğinin değerlendirildiği bir meta-analizde; anjiyotensin dönüştürücü enzim inhibitörleri, anjiyotensin reseptör blokerleri, kalsiyum antagonistleri, beta-blokerler ve diüretikler ile total majör kardiyovasküler olay riski azalmış ancak gruplar arasında fark saptanmamış, kan basıncındaki düşüş miktarı arttıkça riskteki azalma da artmıştır (Turnbull, 2003). Komplikasyonlu hipertansiyonu olmayan çoğu hastada diüretikler ilk tercih edilen ilaç grubudur ve çoklu ilaç kombinasyonlarının ana unsurudur (Ridker ve Libby, 2008).

\section{Hiperlipidemi}

Yüksek kolesterol seviyeleri gelecekteki kardiyovasküler olaylar için kuvvetli bir öngörücüdür. Genetik bozukluklara bağlı olarak çok yüksek LDL kolesterol seviyeleri olan bireylerde prematür aterosklerotik hastalıklar görülmektedir (Goldstein ve ark., 1983). Yüksek LDL kolesterol düzeyleri LDL partiküllerinin damar çeperinde birikmesine, oksidasyonuna ve inflamatuvar mediatörlerin salgılanmasına neden olarak aterosklerozun ana unsuru olan kronik inflamatuvar süreci başlatmaktadır (Maron ve ark., 2008).

Doymuş yağ asitleri/trans yă̆ asitleri/kolesterolü az, doymamış yağ asitleri/bitki sterolü/lifi fazla gıdalardan oluşan diyet ile total ve LDL kolesterol seviyeleri azaltılabilir. Bu tip diyetle koroner arter hastalarında kardiyak ölüm, nonfatal miyokart enfarktüsü, kararsız anjina, kalp yetersizliği ve felç riski azalmaktadır (De Lorgeril ve ark., 1999).

Statinler ile total kolesterol seviyesinin azaltılması koroner endotel fonksiyonlarında iyileşmeye sebep olmaktadır (Treasure ve ark., 1995). Statinler LDL kolesterol seviyesini ortalama \%20-60 düşürmektedir (Ridker ve Libby, 2008). Klinik çalışmalar, statinler ile LDL kolesterol seviyesinin düşürülmesinin koroner olayları azalttığını göstermiştir. İlk başta miyokart enfarktüsü geçirmiş ve yüksek kolesterol seviyeleri olan hastalarda gösterilen bu yarar bilinen aterosklerotik hastalığı olmayan ve ortalama kolesterol değerlerine sahip bireylerde de gösterilmiştir (Sacks ve ark., 1996; Ridker ve ark., 2008a). Statinler ile agresif lipid düşürücü tedavinin daha fazla klinik fayda sağladığı klinik çalışmalarda gösterilmiştir. Treating to New Targets (TNT) çalışmasında, stabil koroner kalp hastalığ tatin tedavisi $10 \mathrm{mg}$ atorvastatine kıyasla çalışmanın primer sonlanım noktası olan ilk majör kardiyovasküler olayın (koroner kalp hastalığından ölüm, nonfatal miyokart enfarktüsü, felç veya kardiyak arrest sonrası resüsitasyon) oluşma riskini $\% 22$ azaltmıştır $(\mathrm{p}<0,001)$ (LaRosa ve ark., 2005).

Sadece yüksek total ve LDL kolesterol seviyelerinin değil yüksek trigliserid seviyesi, küçük ve yoğun LDL partikülleri ve düşük HDL kolesterol seviyesi ile karakterize olan aterojenik dislipideminin de koroner kalp hastalığı riskini arttırdığı iddia edilmektedir. Hastalarda yüksek CRP ve yüksek plasminojen aktivatör inhibitörü-1 seviyeleri saptanmaktadır. Bu durum çoğunlukla obezite, diabetes mellitus ve metabolik sendrom ile ilişkilidir (Maron ve ark., 2008). Aterojenik dislipideminin fibrat ile tedavisi vasküler olay riskini azaltabilmektedir. Yapılan bir meta-analizde bu risk azalması tedavi öncesi serum trigliserid düzeyi $>200 \mathrm{mg} / \mathrm{dL}$ ve $\mathrm{HDL}$ kolesterol düzeyi $<40 \mathrm{mg} / \mathrm{dL}$ olan hastalarda $\% 29$ olarak bulunmuştur ( $\mathrm{p}<0,001)$ (Lee ve ark., 2011). 2 gr/gün nikotinik asit serum trigliserid seviyesini yaklaşık \%20-40 azaltırken, HDL kolesterol seviyesini yaklaşık \%15-35 arttırır (European Association for Cardiovascular Prevention \& Rehabilitation, Reiner ve ark., 2011).

HDL kolesterol seviyesi ile kardiyovasküler risk arasında ters orantı bulunmaktadır. HDL kolesteroldeki $1 \mathrm{mg} / \mathrm{dL}$ artış, total kardiyovasküler riskte yaklaşık \%2-3 azalmaya yol açmaktadır (Ridker ve Libby, 2008). HDL kolesterol, LDL kolesterolün oksidasyonunu önlemekte ve kolesterol transportunu düzenlemektedir (Brewer, 2004). Adult Treatment Panel III'de belirtildiği üzere düşük HDL kolesterol seviyesi ( $<40 \mathrm{mg} / \mathrm{dL})$ pozitif kardiyovasküler risk faktörü olarak kabul edilirken, yüksek HDL kolesterol seviyesi $(\geq 60 \mathrm{mg} / \mathrm{dL})$ ise negatif (koruyucu) kardiyovasküler risk faktörü olarak kabul edilmektedir. National Cholesterol Education Program (NCEP) Expert Panel on Detection, Evaluation, and Treatment of High Blood Cholesterol in Adults (Adult Treatment Panel III), 2002).

\section{Diabetes mellitus}

Diyabetik hastalar koroner kalp hastalığı açısından 4 kat, kardiyovasküler olay açısından 2-4 kat risk artışı altındadır (Greenland ve ark., 2010). Bu hastaların 2/3'ünün ölüm sebebi kardiyovasküler hastalıklardır (Thom ve ark., 2006). Daha önce miyokart enfarktüsü geçirmeyen diyabetik hastanın miyokart enfarktüsü riski, daha önce miyokart enfarktüsü geçiren diyabetik olmayan hastanınkine yakındır (Haffner ve ark., 1998). Diyabetik hastaların koroner arterlerindeki aterosklerotik yük fazladır, aterosklerotik komplikasyonlar hem primer korunmada hem de koroner girişimsel prosedürlerde daha sık görülmektedir (Ridker ve Libby, 2008). İnvaziv olmayan görüntüleme ile saptanan asemptomatik iskemi bazı çalışmalarda diabetik hastaların \%59'unda görülebilmektedir (Greenland ve ark., 2010). Diabetes mellitus koroner kalp hastalığı eşdeğeri olarak kabul edilmektedir (National Cholesterol Education Program (NCEP) Expert Panel on Detection, Evaluation, and Treatment of High Blood Cholesterol in Adults (Adult Treatment Panel III), 2002).

Bozulmuş glukoz toleransı ve/veya bozulmuş açlık glukozu olan bireylerin de sadece diabetes mellitus oluşması açısından değil istenmeyen kardiyovasküler olaylar aç1sından da risk altında olduğu gösterilmiştir (De Fronzo ve Abdul-Ghani, 2011). İnsülin direnci ile karakterize metabolik sendromun artmış vasküler olaylarla ilişkili olduğu birçok çalışmada gösterilmiştir (Grassi ve ark., 2009). Metabolik sendrom tanısı önerilen 5 kriterden en az 3'ünün sağlanması ile konulmaktadır (Alberti ve ark., 2009). Bu kriterler;

1) Irk, ülke ve cinsiyete göre değişen artmış bel çevresi genişliği (Avrupa için erkek $\geq 94 \mathrm{~cm}, \operatorname{kad} ı n \geq 80 \mathrm{~cm}$ ),

2) Serum trigliserid seviyesi $\geq 150 \mathrm{mg} / \mathrm{dL}$ veya spesifik ilaç tedavisi altında olmak,

3) HDL kolesterol seviyesi $<40 \mathrm{mg} / \mathrm{dL}$ (erkek), $<50 \mathrm{mg} /$ dL (kadın) veya spesifik ilaç tedavisi altında olmak,

4) Kan basıncı $\geq 130 / 85 \mathrm{mmHg}$ veya spesifik ilaç tedavisi altında olmak,

5) Serum glukoz seviyesi $\geq 100 \mathrm{mg} / \mathrm{dL}$ veya spesifik ilaç tedavisi altında olmak.

Diabetes mellitus ve insülin direncinin bu negatif etki- 
lerinin patofizyolojik mekanizmaları. İleri glikolizasyon son ürünleri vasküler hasara yol açmaktadır. Endotel ve düz kas hücrelerinin fonksiyonları bozulmakta, vasküler endotele lökosit adezyonu artmaktadır. Mikroalbüminürinin olumsuz etkileri mevcuttur (Ridker ve Libby, 2008). Prokoagülan ve proinflamatuvar durum söz konusudur. Fibrinojen, C-reaktif protein, plasminojen aktivatör inhibitörü-1, von Willebrand faktör seviyeleri ve platelet agregasyonu artmış, fibrinoliz ve nitrik oksit aracılı vazodilatasyon bozulmuştur (Tabit ve ark., 2010). HDL kolesterol düzeyleri düşük, trigliserid ve lipoprotein(a) seviyeleri yüksektir. LDL partikülleri küçük ve yoğundur, lipoprotein oksidasyonu artmıştır (Maron ve ark., 2008). Tüm bunlar aterogenezi tetiklemektedir.

\section{Obezite ve sedanter yaşam}

Obezite sıklığı toplumda giderek artmaktadır. Vücut kitle indeksi $\geq 30 \mathrm{~kg} / \mathrm{m}^{2}$ olan bireyler obez kabul edilmektedir. Direkt veya dolaylı olarak (insülin direnci, hipertansiyon, sol ventrikül hipertrofisi, düşük HDL kolesterol, yüksek trigliserid, küçük yoğun LDL partikülleri, yüksek C-reaktif protein, fiziksel aktivite azlığı, uyku apnesi gibi mekanizmalarla) kardiyovasküler riski arttırır (Poirier ve ark., 2006). Koroner ateroskleroz progresyonunu hızlandırır (McGill ve ark., 2002). Kilo vermek insülin duyarlılığını arttırır, kan basıncını azaltır, trigliserid ve LDL kolesterol seviyesini düşürür, HDL kolesterol seviyesini arttırır (Poirier ve ark., 2006). Fiziksel inaktivite kardiyovasküler riski iki kat arttırmaktadır (Fletcher ve ark., 1996). Düzenli fiziksel aktivite tüm sebeplerden mortalitede \%30-40 azalma yapmaktadır (Knoops ve ark., 2004).

Egzersiz miyokart oksijen gereksinimini azaltır, C-reaktif protein düzeylerini azaltarak vasküler inflamasyonu düzeltir, obezite ve diabetes mellitus riskini azaltır. Endotel disfonksiyonunu ve insülin direncini iyileştirir, platelet agregasyonunu azaltarak ve fibrinolizisi arttırarak prokoagülan sistemi düzenler, kan basıncını düşürür (Thompson ve ark., 2003). Dislipidemiyi düzeltir. Özellikle HDL kolesterol seviyesini yükseltir, trigliserid seviyesini düşürür. LDL partiküllerinin büyüklügünü arttırır (Kraus ve ark., 2002). Anjiyografik olarak saptanmış koroner aterosklerozun ilerlemesini yavaşlatır (Fletcher ve ark., 1996). Egzersiz tüm bu mekanizmalarla kardiyovasküler riski azaltmaktadır. Harcanan enerji miktarı aynı olmak şartıyla kısa egzersiz süreleri de uzun egzersiz süreleri kadar kardiyovasküler riski azaltmaktadır (Lee ve ark., 2000).

\section{Stres}

Mental stres adrenerjik stimülasyon, miyokart oksijen ihtiyacının artmas1, koroner vazokonstriksiyon, platelet ve endotel disfonksiyonu, malign aritmilerin tetiklenmesi gibi mekanizmalarla kardiyovasküler riski arttırmaktadır (Proietti ve ark., 2011). Benzer şekilde iş stresi de bu riski arttırmaktadır (Kivimäki ve ark., 2002). Yapılan bir meta-analizde, klinik olarak depresyonu olan hastalarda koroner kalp hastalığ oluşma riskinin diğer faktörlerden bağımsız olarak 2,6 kat arttığ1 saptanmıştır (Rugulies, 2002). Düşük sosyoekonomik düzey de farklı mekanizmalarla (sigara, hipertansiyon, obezite, sedanter yaşam gibi risk faktörlerinin fazla olması, sağlık hizmetlerine ulaşmada zorluk, eğitim eksikliği, sağlıksız beslenme ve psikososyal stres) kardiyovasküler risk artışına sebep olmaktadır (Kaplan ve Keil, 1993).

\section{Yeni risk faktörleri}

Koroner kalp hastalarının \%15-20'sinde klasik risk faktörleri bulunmamaktadır. Yaklaşık \%40'ında ise sadece tek bir risk faktörü bulunmaktadır (Khot ve ark., 2003). Özellikle klasik risk faktörlerini kullanan risk skorları ile 10 yıllık istenmeyen kardiyovasküler olay riski orta düzeyde olan hastalarda daha ileri risk değerlendirmesine ihtiyaç duyulmaktadır. Bu durum yeni aterosklerotik risk faktörlerinin araştırılmasına neden olmaktadır.

\section{Yüksek duyarlı C-Reaktif Protein (CRP)}

Plak oluşumunda ve plak rüptüründe inflamasyon kritik bir role sahiptir. Bu nedenle akut faz reaktanı olan CRP'nin risk faktörü olarak kullanılabileceği ileri sürülmektedir. CRP'nin lokal adezyon moleküllerinin sentezini tetikleyerek, endotelyal nitrik oksid aktivitesini azaltarak, makrofajlar tarafından LDL kolesterol alımını değişikliğe uğratarak ve intravasküler trombozu uyararak direkt proinflamatuvar etkilerinin olduğuna dair kanıtlar da mevcuttur (Ridker ve Libby, 2008).

Hipertansiyon, obezite, sigara, metabolik sendrom, diabetes mellitus, düşük HDL kolesterol ve yüksek trigliserid seviyeleri ile CRP düzeyleri artar. Fiziksel aktivite, kilo verme, diyet ve sigaranın bırakılması düzeyleri azaltır (Pearson ve ark., 2003). CRP, Framingham Risk Skoru ile belirlenen tüm risk seviyelerinde bağımsız prognostik katkı sağlamaktadır (Ridker ve ark., 2002). Klasik risk skorlamasına yüksek duyarlı CRP'nin eklenmesi orta riskli olarak sınıflandırılmış hastaların gerçek risk kategorisinin saptanmasına olanak sağlamaktadır. Sağlıklı bireylerde yüksek CRP düzeyleri gelecekteki koroner arter hastalığı için güçlü bir öngörücüdür (Boekholdt ve ark., 2006). Vasküler risk artışı sadece koroner kalp hastalığg ile sınırlı olmayıp felç, periferik arter hastalığı, kalp yetersizliği, atrial fibrilasyon, ani ölüm ve mortaliteyi de kapsamaktadır (Greenland ve ark., 2010). CRP düzeyleri yüksek hastalar agresif girişimsel tedavi stratejilerinden daha fazla fayda görmektedir (Cohen ve ark., 2006). $3 \mathrm{mg} / \mathrm{L}$ 'den fazla değerlerin yüksek vasküler risk, 1-3 mg/L aralığındaki değerlerin orta vasküler risk ve $1 \mathrm{mg} / \mathrm{L}$ 'den az değerlerin düşük vasküler risk ile ilişkili olduğu bildirilmiştir (Pearson ve ark., 2003). Çok yüksek değerler altta yatan inflamatuvar hastalığa (romatoid artrit gibi) ya da enfeksiyona bağlı olabilir, bu nedenle 2-3 hafta sonra test tekrarlanmalıdır.

Yapılan bir meta-analizde, bireysel koroner kalp hastal1ğ1 olay riskinin yeniden gruplandırılmasında CRP'nin standart risk tahmin modellerine olan katkısının orta derecede ve değişken olduğu gösterilmiştir (Shah ve ark., 2009). Tüm bu veriler 1şığında, ACCF/AHA asemptomatik orta riskli hastalarda kardiyovasküler risk değerlendirmesi için CRP ölçümünün düşük sınıf ve kanıt düzeyi ile yapılabileceğini bildirmiştir (Sınıf IIb, Kanıt Düzeyi B) (Greenland ve ark., 2010). Aynı kılavuzda asemptomatik yüksek riskli hastalarda kardiyovasküler risk değerlendirmesi için CRP ölçümü önerilmemektedir (Sınıf III, Kanıt Düzeyi B). Düşük riskli hastalarda da (erkek $<50$ yaş, kadın $<60$ yaş) kardiyovasküler risk değerlendirmesi için CRP ölçümü önerilmemektedir (Sınıf III, Kanıt Düzeyi B).

LDL kolesterolü düşürme etkilerinden bağımsız olarak statinler yüksek duyarlı CRP düzeylerini azaltırlar (Ridker ve ark., 1999). Böylece statinler sadece kolesterol seviyesi yüksek hastalarda değil yüksek duyarlı CRP seviyesi yüksek 
hastalarda da vasküler olayları önleyebilirler. Tedavi ile CRP düzeyleri düştükçe elde edilen klinik yarar da artmaktadır. 15548 sağlıklı katılımcının değerlendirildiği JUPITER çalışmasında, $20 \mathrm{mg}$ rosuvastatin ile yüksek duyarlı CRP düzeyleri $2 \mathrm{mg}$ /L'nin altına inenlerde plaseboya kıyasla kardiyovasküler olaylarda ortalama 1,9 yıllık takip süresinde $\% 62$ azalma meydana gelmiştir ( $\mathrm{p}<0,0001)$ (Ridker ve ark., 2009). Akut koroner sendromlu 3745 hastanın dahil edildiği PROVE IT-TIMI 22 çalışmasında, statin tedavisi ile CRP düzeyleri 2 $\mathrm{mg} / \mathrm{L}$ 'nin altına inenlerde daha yüksek CRP seviyesi olanlara kıyasla kardiyovasküler olay riski anlamlı olarak azalmıştır ( $\mathrm{p}=0,006)$ (Ridker ve ark., 2005).

Yüksek duyarlı CRP düzeyleri statin tedavisine başlama zamanını belirlemek için de kullanılabilir. ACCF/AHA, LDL kolesterolü $<130 \mathrm{mg} / \mathrm{dL}$ olan; lipid düşürücü tedavi, hormon replasman tedavisi veya immünosüpresan tedavi almayan; klinik koroner kalp hastalığı, diabetes mellitus, kronik böbrek hastalığ 1 , ciddi inflamatuvar durum ve statinlere kontraendikasyonu olmayanlarda (erkek $\geq 50$ yaş, kadın $\geq 60$ yaş) statin tedavisi için hasta seçiminde CRP ölçümünün faydalı olabileceğini bildirmiştir (Sınıf IIa, Kanıt Düzeyi B) (Greenland ve ark., 2010).

\section{Homosistein}

Normal açlik homosistein düzeyleri 5-15 $\mu \mathrm{mol} / \mathrm{L}$ 'dir. Plazma seviyesi en fazla diyetteki folik asit, vitamin B6 ve B12 miktarından etkilenir. Ancak ileri yaş, menapoz, sigara, erkek cinsiyet, alkol ve bazı ilaçlar da hiperhomosisteinemiye sebep olabilir (Maron ve ark., 2008). Metionin metabolizmasındaki genetik bozukluklara bağlı olarak homosistein düzeyleri aşırı yüksek olan bireylerde prematür ateroskleroz riski artmaktadir (Della-Morte ve ark., 2010). Bu duruma endotel disfonksiyonu, LDL kolesterol oksidasyonu, vazodilatasyonun bozulması, platelet aktivasyonu ve oksidatif stres gibi faktörlerin sebep olduğu düşünülmektedir (Wilson ve Lentz, 2005).

Homosistein düzeylerinin azaltılması ile kardiyovasküler olay riskinin azaltılabileceği ileri sürülmüştür (Wang ve ark., 2007). Ancak vasküler hastalığı veya diabetes mellitusu olan 5522 hastanın değerlendirildiği HOPE-2 çalışmasında folik asit ve B vitaminleri ile homosistein düzeylerinin azaltılması kardiyovasküler sebeplerden ölüm, miyokart enfarktüsü ve felç riskini azaltmamıştır (Lonn ve ark., 2006). 37485 hastanın verilerinin değerlendirildiği bir meta-analizde de folik asit ile homosistein düzeylerinin azaltılması majör vasküler olayları ve mortaliteyi azaltmamıştır (Clarke ve ark., 2010). Klasik risk faktörleri olmayan, ancak genç yaşta kardiyovasküler hastalığı olan bireylerde homosistein seviyeleri kontrol edilebilir.

\section{Fibrinojen/d-dimer/doku tipi plasminojen aktivatö-} rü/ plasminojen aktivatör inhibitörü-1

Fibrinojen bir akut faz reaktanıdır. Yüksek fibrinojen seviyeleri kan viskositesini arttırır, platelet agregasyonunu tetikler. Sigara, ileri yaş ve diabetes mellitus seviyesini arttırırken, fiziksel aktivite azaltır (Maron ve ark., 2008). CRP gibi yüksek fibrinojen seviyelerinin de kardiyovasküler olay riskiyle ilişkili olduğu gösterilmiştir. Fibrinojen seviyesindeki 1 $\mathrm{g} / \mathrm{L}$ artış kardiyovasküler hastalık ve mortalite riskini 2,0-2,7 kat arttırmaktadır (Fibrinogen Studies Collaboration, Danesh ve ark., 2005).
Doku plasminojen aktivatörü antijeni ve plasminojen aktivatör inhibitörü-1 seviyeleri artmış aterotromboz riskine sebep olmaktadır (Pradhan ve ark., 2004; Vaughan, 2005).

Fibrin yıkım ürünlerinden olan D-dimer'in de vasküler riski öngördüğü saptanmıştır. Akut iskemik göğüs ağrısı olan hastalarda artmış D-dimer düzeyleri miyokart enfarktüsü ve ölüm riskini 5,4 kat arttırmaktadır (Menown ve ark., 2003). Prematür koroner arter hastalığı olan bireylerin yakınlarında D-dimer ve doku plasminojen aktivatörü seviyeleri yüksek bulunmuştur (Mills ve ark., 2002). Metabolik sendromda ve diabetes mellitusda doku plasminojen aktivatörü antijeni ve plasminojen aktivatör inhibitörü-1 seviyeleri artmaktadır (Al-Hamodi ve ark., 2011). Standart laboratuvar ölçüm tekniklerinin olmaması bu belirteçlerin klinik kullanımlarını sınırlamaktadır.

\section{Lipoprotein (a)}

Yapısında bulunan apolipoproteinin plasminojen ile olan benzerliği nedeniyle lipoprotein(a)'nın plasminojenin kompetitif inhibitörü olduğu ileri sürülmektedir (Scanu, 1992). Böylece endojen fibrinolizisi önleyerek, doku faktörü yolu inhibitörünü inaktive ederek, plasminojen aktivatör inhibitörü seviyelerini arttırarak aterotromboza katkıda bulunduğu iddia edilmektedir (Vucković ve Derić, 2007). Yapılan bir meta-analizde lipoprotein(a) seviyesi ile koroner kalp hastalığı ve felç arasında devamlı, bağımsız, fakat orta derecede bir ilişki saptanmıştır (Emerging Risk Factors Collaboration, Erqou ve ark., 2009). Başka bir meta-analizde de, yüksek lipoprotein(a) seviyelerinin düşük seviyelere kıyasla 1,6 kat artmış koroner kalp hastalığı riski ile ilişkili olduğu gösterilmiştir ( $<<0,00001)$ (Danesh ve ark., 2000). Özellikle kardiyovasküler risk faktörleri fazla olan bireylerde prognostik değerinin arttığ1 gösterilmiştir (Solfrizzi ve ark., 2002). Ancak lipoprotein(a) seviyelerinin düşürülmesi ile vasküler riskin azaldığına dair tatmin edici veriler mevcut değildir. Standart laboratuvar ölçüm tekniklerinin olmaması bu belirteçin klinik kullanımını sınırlamaktadır. $\mathrm{Bu}$ nedenlerden dolayı ACCF/ AHA, asemptomatik hastalarda risk değerlendirmesi için lipoprotein seviyelerinin ölçümünü önermemektedir (Sınıf III, Kanıt Düzeyi C) (Greenland ve ark., 2010).

\section{Karotis intima-media kalınlığı}

Yapılan klinik çalışmalarda karotis intima-media kalınlığının koroner kalp hastalığı ve felç için bağımsız bir öngörücü olduğu gösterilmiştir (Simon ve ark., 2010). Ölçümlerin yüksek kalitede olması için ekipman, teknik, operatör eğitimi ve deneyim konusunda yayınlanmış önerilere uyulması çok önemlidir (Greenland ve ark., 2010). Yapılan bir çalışmada kalınlıktaki her $0,03 \mathrm{~mm} / \mathrm{y} ı 1$ artış nonfatal akut miyokart enfarktüsü, koroner ölüm veya koroner arter revaskülarizasyon için rölatif riski 3,1 kat arttırmıştır $(\mathrm{p}<0,001)$ (Hodis ve ark., 1998). Yapılan bir meta-analizde de kalınlıktaki her 0,1 mm'lik artışın miyokart enfarktüsü riskini $\% 15$, felç riskini ise \%18 arttırdığı bulunmuştur (Lorenz ve ark., 2007). Özellikle orta riskli hastalarda (10 yıllık koroner kalp hastalığı istenmeyen olay riski \%10-20) risk kategorisinin yeniden sınıflandırılmasına katkı sağlayabilmektedir (Nambi ve ark., 2010).

Kolesterol düşürücü ilaçlar ve geleneksel risk faktörlerinin azaltılması ilerleme hızını yavaşlatabilir. ARBITER 6-HALTS çalışmasında statin tedavisi alan ve koroner arter 
hastalığ1 veya koroner arter hastalığı eşdeğeri olan, LDL kolesterol seviyesi $<100 \mathrm{mg} / \mathrm{dL}$ ve HDL kolesterol seviyesi $<50-55 \mathrm{mg} / \mathrm{dL}$ olan hastalar yavaş salınımlı niasin $(2000 \mathrm{mg} /$ gün) veya ezetimib (10 mg/gün) gruplarına randomize edilmiştir. Niasin karotis intima-media kalınlığında gerilemeye yol açmış, ezetimibten üstün bulunmuştur (Villines ve ark., 2010). METEOR çalışmasında ise subklinik aterosklerozu olan asemptomatik bireylerde $(\mathrm{n}=984) 40 \mathrm{mg} /$ gün rosuvastatin tedavisi plaseboya kıyasla karotis intima-media kalınlığ 1 ilerleme hızında azalmaya yol açmıştır (Crouse ve ark., 2007). Ancak 18307 hastayla yapılan bir meta-analizde, kardiyovasküler ilaç tedavisi yapılan hastalarda karotis intima-media kalınlığının gerilemesi veya ilerleme hızının yavaşlatılması ile kardiyovasküler olaylardaki azalma arasında ilişki olmadığı gösterilmiştir (Costanzo ve ark., 2010). Yine de ACCF/ AHA, orta riskli asemptomatik hastalarda kardiyovasküler risk değerlendirmesi için karotis intima-media kalınlığının ölçülebileceğini bildirmektedir (Sınıf IIa, Kanıt Düzeyi B) (Greenland ve ark., 2010).

\section{Bilgisayarlı tomografi ile saptanan koroner arter kalsiyum skoru}

Koroner arterlerdeki total kalsiyum miktarı arttıkça (kalsiyum skoru $>100$ ), gelecekteki koroner kalp hastalığı olay riski de artmaktadır (Budoff ve Gul, 2008). Koroner kalsiyum skoru yıllık >\%15 arttığında, miyokart enfarktüsü riski yaklaşık 17 kat artış göstermektedir (Raggi ve ark., 2004). Kalsiyum skorlaması koroner aterosklerozun saptanmasında yüksek sensitivite değerine sahipken, tıkayıcı koroner arter darlıklarının saptanmasında düşük spesifite değerine sahiptir (Budoff ve Gul, 2008). Koroner olayların çoğundan sorumlu olan ince kapsüllü, kalsifik olmayan plakların saptanmasında bu yöntem başarısız kalmaktadır. Dolayısıyla, tek başına koroner kalsiyum skorunun düşük olması hastanın düşük riskli olacağı anlamına gelmemektedir. Uygulanan radyasyon ve genç hastalarda koroner kalsifikasyon ihtimalinin düşük olması nedeniyle erkeklerde 40 yaşından önce, kadınlarda 50 yaşından önce kullanımı önerilmemektedir (Greenland ve ark., 2010). ACCF/AHA orta riskli asemptomatik bireylerde kardiyovasküler risk değerlendirmesi için koroner kalsiyum skorunun ölçülebileceğini bildirmiştir (Sınıf IIa, Kanıt Düzeyi B) (Greenland ve ark., 2010).

\section{Manyetik rezonans görüntüleme ile aterosklerotik plak analizi}

İyonize radyasyon olmadan manyetik rezonans ile aterosklerotik plak yapılarının doku karakterizasyonu (nekrotik lipid çekirdek, fibröz kapsül bileşimi, kanama, kalsifikasyon) yapılabilmekte, böylece yüksek riskli plaklar saptanabilmektedir (Choudhury ve ark., 2002). Torakoabdominal manyetik rezonans ile saptanan ve subklinik aterosklerozu gösteren plak sıklığı ve yükünün Framingham Risk Skoru ile korele olduğu saptanmıştır (Jaffer ve ark., 2002). Bu görüntüleme tekniği ile yapılmış klinik prospektif çalışmalar sınırlı ve sonuçları net olmadığ i için asemptomatik hastalarda kardiyovasküler risk değerlendirmesi için manyetik rezonans ile vasküler plak görüntülenmesi önerilmemektedir (Sınıf III, Kanıt Düzeyi C) (Greenland ve ark., 2010).

\section{Risk skorları}

Aterosklerotik kardiyovasküler hastalık çok sayıda risk faktörünün etkileşmesi sonucu ortaya çıkmakta ve ilerlemek- tedir. $\mathrm{Bu}$ nedenle ACCF/AHA'ya göre geleneksel kardiyovasküler risk faktörlerini kullanan risk skorları koroner kalp hastalığı hikâyesi olmayan tüm asemptomatik yetişkinlerde risk değerlendirmesi için kullanılabilir. Buradan elde edilen sonuçlar önleyici girişimleri uygulamada faydalıdır (Sınıf I, Kanıt Düzeyi B) (Greenland ve ark., 2010). En sık kullanılan risk skorları Framingham, SCORE, PROCAM ve Reynolds Risk Skorları'dır.

Framingham Risk Skoru'nda değerlendirilen risk faktörleri yaş, cinsiyet, total kolesterol seviyesi, HDL kolesterol seviyesi, sistolik kan basınc1/yüksek tansiyon için ilaç kullanma ve sigaradır. Framingham Risk Skoru'nun değişik versiyonları yayınlanmıştır. Bunların bir kısmında diabetes mellitus risk faktörü olarak dahil edilirken Adult Treatment Panel III'de yayınlanan versiyonunda risk faktörü olarak dahil edilmemiştir (National Cholesterol Education Program (NCEP) Expert Panel on Detection, Evaluation, and Treatment of High Blood Cholesterol in Adults (Adult Treatment Panel III), 2002). Benzer şekilde sonlanım noktası versiyonların bir kısmında koroner kalp hastalığından ölüm ve nonfatal miyokart enfarktüsü olarak kabul edilirken bazılarında total kardiyovasküler olaylar olarak kabul edilmiştir. Bir popülasyonda geliştirilen risk skoru diğer popülasyonlar için uygun olmayabilir. Bu tür durumlarda skorun kalibrasyonu için 'prevalans düzeltmesi' gerekebilir (D'Agostino ve ark., 2001).

Framingham Risk Skoru'nda hastalar yüksek, orta ve düşük riskli olarak 3 kategoriye ayrılmaktadır. 10 yıllık istenmeyen olay riski $>\% 20$ olan hastalar yüksek riskli, \%10-20 olanlar orta riskli ve $<\% 10$ olanlar düşük riskli olarak kabul edilmektedir (Greenland ve ark., 2010). Web üzerinden risk skoru hesaplayıcısına'http://hp2010.nhlbihin.net/atpiii/calculator.asp? usertype=prof' adresinden ulaşllabilmektedir.

SCORE Risk Skoru'nda değerlendirmede yaş, cinsiyet, total kolesterol seviyesi (veya total kolesterol/HDL kolesterol oranı), sigara ve sistolik kan basıncı kullanılır. Ayrıca kardiyovasküler hastalık riski yüksek veya düşük popülasyonlara göre farklı hesap tabloları bulunmaktadır. Sonlanım noktası 10 yıllık ilk fatal kardiyovasküler olay riskidir (Conroy ve ark., 2003). 10 yıllık istenmeyen olay riski $\geq \% 10$ olanlar çok yüksek riskli, $<\% 10-\geq \% 5$ olanlar yüksek riskli, $<\% 5-\geq \% 1$ olanlar orta riskli, $<\% 1$ olanlar düşük riskli olarak kabul edilmektedir (European Association for Cardiovascular Prevention \& Rehabilitation, Reiner ve ark., 2011). Web üzerinden risk skoru hesaplayıcısına ' $h$ ttp://www.heartscore.org/Pages/ welcome.aspx' adresinden ulaşllabilmektedir.

Reynolds Risk Skoru'nda değerlendirmede yaş, cinsiyet, sigara, sistolik kan basinc1, total ve HDL kolesterol seviyeleri, diabetes mellitus varlığında HbA1c, aile öyküsü (60 yaşından önce miyokart enfarktüsü öyküsü) ve yüksek duyarlı CRP düzeyi kullanılır. Sonlanım noktası 10 yıllık miyokart enfarktüsü, felç, koroner revaskülarizasyon ve kardiyovasküler ölüm riskidir (Ridker ve ark., 2008b). Web üzerinden risk skoru hesaplayıcısına 'http:/Www.reynoldsriskscore.org/' adresinden ulaşılabilmektedir.

PROCAM Risk Skoru'nda yaş, LDL ve HDL kolesterol seviyeleri, trigliserid seviyesi, sigara, diabetes mellitus, sistolik kan basıncı ve ailede prematür miyokart enfarktüsü öyküsü değerlendirilir. Sonlanım noktası 10 yıllık miyokart enfarktüsü ve ani kardiyak ölüm riskidir (Assmann ve ark., 2002). Web üzerinden risk skoru hesaplayıcısına 'http:// www.chd-taskforce.com/coronary_risk_assessment.html' adresinden ulaşılabilmektedir. 


\section{KAYNAKLAR}

Alberti, K.G., Eckel, R.H., Grundy, S.M., Zimmet, P.Z., Cleeman, J.I., Donato, K.A., Fruchart, J.C., James, W.P., Loria, C.M., Smith, S.C.Jr., 2009. International diabetes federation task force on epidemiology and prevention; national heart, lung, and blood institute; American heart association; world heart federation; international atherosclerosis society; international association for the study of obesity. Harmonizing the metabolic syndrome: A joint interim statement of the international diabetes federation task force on epidemiology and prevention; national heart, lung, and blood institute; American heart association; world heart federation; international atherosclerosis society; and international association for the study of obesity. Circulation. 120, 1640-1645.

Al-Hamodi, Z., Ismail, I.S., Saif-Ali, R., Ahmed, K.A., Muniandy, S., 2011. Association of plasminogen activator inhibitor-1 and tissue plasminogen activator with type 2 diabetes and metabolic syndrome in Malaysian subjects. Cardiovasc. Diabetol. 10, 23.

Allender, S., Scarborough, P., Peto, V., Rayner, M., Leal, J., Luengo-Fernandez, R., Gray, A., 2008. European cardiovascular disease statistics, 2008 ed. European Heart Network.

Assmann, G., Cullen, P., Schulte, H., 2002. Simple scoring scheme for calculating the risk of acute coronary events based on the 10-year followup of the prospective cardiovascular Münster (P.R.O.C.A.M.) study. Circulation. 105, 310-315.

Barua, R.S., Ambrose, J.A., Srivastava, S., DeVoe, M.C., Eales-Reynolds, L.J., 2003. Reactive oxygen species are involved in smoking-induced dysfunction of nitric oxide biosynthesis and upregulation of endothelial nitric oxide synthase: An in vitro demonstration in human coronary artery endothelial cells. Circulation. 107, 2342-2347.

Bazzano, L.A., He, J., Muntner, P., Vupputuri, S., Whelton, P.K., 2003. Relationship between cigarette smoking and novel risk factors for cardiovascular disease in the United States. Ann. Intern. Med. 138, 891-897.

Boekholdt, S.M., Hack, C.E., Sandhu, M.S., Luben, R., Bingham, S.A., Wareham, N.J., Peters, R.J., Jukema, J.W., Day, N.E., Kastelein, J.J., Khaw, K.T., 2006. C-reactive protein levels and coronary artery disease incidence and mortality in apparently healthy men and women: The EPIC-Norfolk prospective population study 1993-2003. Atherosclerosis. 187, 415-422.

Brewer, H.B.Jr., 2004. Increasing HDL cholesterol levels. N. Engl. J. Med. 350, 1491-1494.

Budoff, M.J., Gul, K.M., 2008. Expert review on coronary calcium. Vasc. Health Risk Manag. 4, 315-324.

Chobanian, A.V., Bakris, G.L., Black, H.R., Cushman, W.C., Green, L.A., Izzo, J.L.Jr., Jones, D.W., Materson, B.J., Oparil, S., Wright, J.T.Jr., Roccella, E.J., 2003. National heart, lung, and blood institute joint national committee on prevention, detection, evaluation, and treatment of high blood pressure; national high blood pressure education program coordinating committee. The seventh report of the joint national committee on prevention, detection, evaluation, and treatment of high blood pressure: The jnc 7 report. JAMA. 289, 2560-2572.

Choudhury, R.P., Fuster, V., Badimon, J.J., Fisher, E.A., Fayad, Z.A., 2002. MRI and characterization of atherosclerotic plaque: Emerging applications and molecular imaging. Arterioscl. Throm. Vas. Biol. 22, 1065-1074.

Clarke, R., Halsey, J., Lewington, S., Lonn, E., Armitage, J., Manson, J.E., Bønaa, K.H., Spence, J.D., Nygård, O., Jamison, R., Gaziano, J.M., Guarino, P., Bennett, D., Mir, F., Peto, R., Collins, R., 2010. B-Vitamin treatment trialists' collaboration. Effects of lowering homocysteine levels with B vitamins on cardiovascular disease, cancer, and cause-specific mortality: Meta-analysis of 8 randomized trials involving 37485 individuals. Arch. Intern. Med. 170, 1622-1631.

Cohen, M., Diez, J., Fry, E., Rao, S.V., Ferguson, J.J.3rd., Zidar, J., Levine, G., Shani, J., 2006. Strategies for optimizing outcomes in the NSTEACS patient The CATH (cardiac catheterization and antithrombotic therapy in the hospital) Clinical consensus panel report. J. Invasive Cardiol. 18, 617-639.

Collins, R., MacMahon, S., 1994. Blood pressure, antihypertensive drug treatment and the risks of stroke and of coronary heart disease. Br. Med. Bull. 50, 272-298.

Conroy, R.M., Pyörälä, K., Fitzgerald, A.P., Sans, S., Menotti, A., De Backer, G., De Bacquer, D., Ducimetière, P., Jousilahti, P., Keil, U., Njølstad, I., Oganov, R.G., Thomsen, T., Tunstall-Pedoe, H., Tverdal, A., Wedel, H., Whincup, P., Wilhelmsen, L., Graham, I.M., 2003. SCORE project group. Estimation of ten-year risk of fatal cardiovascular disease in Europe: The SCORE project. Eur. Heart J. 24, $987-1003$.

Costanzo, P., Perrone-Filardi, P., Vassallo, E., Paolillo, S., Cesarano, P., Brevetti, G., Chiariello, M., 2010. Does carotid intima-media thickness regression predict reduction of cardiovascular events? A meta-analysis of 41 randomized trials. J. Am. Coll. Cardiol. 56, 2006-2020.

Critchley, J.A., Capewell, S., 2003. Mortality risk reduction associated with smoking cessation in patients with coronary heart disease: A systematic review. JAMA. 290, 86-97.

Crouse, J.R.3rd., Raichlen, J.S., Riley, W.A., Evans, G.W., Palmer, M.K., O'Leary, D.H., Grobbee, D.E., Bots, M.L., 2007. METEOR Study Group. Effect of rosuvastatin on progression of carotid intima-media thickness in low-risk individuals with subclinical atherosclerosis: The METEOR Trial. JAMA. 297, 1344-1353.

D'Agostino, R.B.Sr., Grundy, S., Sullivan, L.M., Wilson, P., 2001. CHD Risk Prediction Group. Validation of the Framingham coronary heart disease prediction scores: Results of a multiple ethnic groups investigation. JAMA. 286, 180-187.

Danesh, J., Collins, R., Peto, R., 2000. Lipoprotein(a) and coronary heart disease. Meta-analysis of prospective studies. Circulation. 102, 10821085.

De Fronzo, R.A., Abdul-Ghani, M., 2011. Assessment and treatment of cardiovascular risk in prediabetes: Impaired glucose tolerance and impaired fasting glucose. Am. J. Cardiol. 108, 3-24.

Della-Morte, D., Beecham, A., Rundek, T., Slifer, S., Boden-Albala, B., McClendon, M.S., Blanton, S.H., Sacco, R.L., 2010. Genetic linkage of serum homocysteine in Dominican families: The family study of stroke risk and carotid atherosclerosis. Stroke. 41, 1356-1362.

De Lorgeril, M., Salen, P., Martin, J.L., Monjaud, I., Delaye, J., Mamelle, N., 1999. Mediterranean diet, traditional risk factors, and the rate of cardiovascular complications after myocardial infarction: Final report of the lyon diet heart study. Circulation. 99, 779-785.

Erqou, S., Kaptoge, S., Perry, P.L., Di Angelantonio, E., Thompson, A., White, I.R., Marcovina, S.M., Collins, R., Thompson, S.G., Danesh, J., 2009. Emerging risk factors collaboration. lipoprotein(a) concentration and the risk of coronary heart disease, stroke, and nonvascular mortality. JAMA. 302, 412-423.

European Association for Cardiovascular Prevention \& Rehabilitation, Reiner, Z., Catapano, A.L., De Backer, G., Graham, I., Taskinen, M.R., Wiklund, O., Agewall, S., Alegria, E., Chapman, M.J., Durrington, P., Erdine, S., Halcox, J., Hobbs, R., Kjekshus, J., Filardi, P.P., Riccardi, G., Storey, R.F., Wood, D.; ESC Committee for Practice Guidelines (CPG) 2008-2010 and 2010-2012 Committees, Bax, J., Vahanian, A., Auricchio, A., Baumgartner, H., Ceconi, C., Dean, V., Deaton, C., Fagard, R., Filippatos, G., Funck-Brentano, C., Hasdai, D., Hobbs, R., Hoes, A., Kearney, P., Knuuti, J., Kolh, P., McDonagh, T., Moulin, C., Poldermans, D., Popescu, B.A., Reiner, Z., Sechtem, U., Sirnes, P.A., Tendera, M., Torbicki, A., Vardas, P., Widimsky, P., Windecker, S., Funck-Brentano, C., Poldermans, D., Berkenboom, G., De Graaf, 
J., Descamps, O., Gotcheva, N., Griffith, K., Guida, G.F., Gulec, S., Henkin, Y., Huber, K., Kesaniemi, Y.A., Lekakis, J., Manolis, A.J., Marques-Vidal, P., Masana, L., McMurray, J., Mendes, M., Pagava, Z., Pedersen, T., Prescott, E., Rato, Q., Rosano, G., Sans, S., Stalenhoef, A., Tokgozoglu, L., Viigimaa, M., Wittekoek, M.E., Zamorano, J.L., 2011. ESC/EAS Guidelines for the management of dyslipidaemias: The task force for the management of dyslipidaemias of the european society of cardiology (E.S.C.) and the European Atherosclerosis Society (E.A.S.). Eur. Heart J. 32, 1769-1818.

Fibrinogen Studies Collaboration, Danesh, J., Lewington, S., Thompson, S.G., Lowe, G.D., Collins, R., Kostis, J.B., Wilson, A.C., Folsom, A.R., Wu, K., Benderly, M., Goldbourt, U., Willeit, J., Kiechl, S., Yarnell, J.W., Sweetnam, P.M., Elwood, P.C., Cushman, M., Psaty, B.M., Tracy, R.P., Tybjaerg-Hansen, A., Haverkate, F., de Maat, M.P., Fowkes, F.G., Lee, A.J., Smith, F.B., Salomaa, V., Harald, K., Rasi, R., Vahtera, E., Jousilahti, P., Pekkanen, J., D'Agostino, R., Kannel, W.B., Wilson, P.W., Tofler, G., Arocha-Piñango, C.L., Rodriguez-Larralde, A., Nagy, E., Mijares, M., Espinosa, R., Rodriquez-Roa, E., Ryder, E., Diez-Ewald, M.P., Campos, G., Fernandez, V., Torres, E., Marchioli, R., Valagussa, F., Rosengren, A., Wilhelmsen, L., Lappas, G., Eriksson, H., Cremer, P., Nagel, D., Curb, J.D., Rodriguez, B., Yano, K., Salonen, J.T., Nyyssönen, K., Tuomainen, T.P., Hedblad, B., Lind, P., Loewel, H., Koenig, W., Meade, T.W., Cooper, J.A., De Stavola, B., Knottenbelt, C., Miller, G.J., Cooper, J.A., Bauer, K.A., Rosenberg, R.D., Sato, S., Kitamura, A., Naito, Y., Palosuo, T., Ducimetiere, P., Amouyel, P., Arveiler, D., Evans, A.E., Ferrieres, J., Juhan-Vague, I., Bingham, A., Schulte, H., Assmann, G., Cantin, B., Lamarche, B., Després, J.P., Dagenais, G.R., Tunstall-Pedoe, H., Woodward, M., Ben-Shlomo, Y., Davey Smith, G., Palmieri, V., Yeh, J.L., Rudnicka, A., Ridker, P., Rodeghiero, F., Tosetto, A., Shepherd, J., Ford, I., Robertson, M., Brunner, E., Shipley, M., Feskens, E.J., Kromhout, D., Dickinson, A., Ireland, B., Juzwishin, K., Kaptoge, S., Lewington, S., Memon, A., Sarwar, N., Walker, M., Wheeler, J., White, I., Wood, A., 2005. Plasma fibrinogen level and the risk of major cardiovascular diseases and nonvascular mortality: An individual participant meta-analysis. JAMA. 294, $1799-1809$.

Fletcher, G.F., Balady, G., Blair, S.N., Blumenthal, J., Caspersen, C., Chaitman, B., Epstein, S., Sivarajan Froelicher, E.S., Froelicher, V.F., Pina, I.L., Pollock, M.L., 1996. Statement on exercise: Benefits and recommendations for physical activity programs for all Americans. A statement for health professionals by the committee on exercise and cardiac rehabilitation of the council on clinical cardiology, American Heart Association. Circulation. 94, 857-862.

Godtfredsen, N.S., Holst, C., Prescott, E., Vestbo, J., Osler, M., 2002. Smoking reduction, smoking cessation, and mortality: A 16-year follow-up of 19,732 men and women from The Copenhagen centre for prospective population studies. Am. J. Epidemiol. 156, 994-1001.

Goldstein, J.L., Kita, T., Brown, M.S., 1983. Defective lipoprotein receptors and atherosclerosis. Lessons from an animal counterpart of familial hypercholesterolemia. N. Engl. J. Med. 309, 288-296.

Gordon, T., Kannel, W.B., McGee, D., Dawber, T.R., 1974. Death and coronary attacks in men after giving up cigarette smoking. A report from the Framingham study. Lancet. 2, 1345-1348.

Grassi, G., Seravalle, G., Quarti-Trevano, F., Dell'Oro, R., Bombelli, M., Mancia, G., 2009. Metabolic syndrome and cardiometabolic risk: An update. Blood Press. 18, 7-16.

Greenland, P., Alpert, J.S., Beller, G.A., Benjamin, E.J., Budoff, M.J., Fayad, Z.A., Foster, E., Hlatky, M.A., Hodgson, J.M., Kushner, F.G., Lauer, M.S., Shaw, L.J., Smith, S.C.Jr., Taylor, A.J., Weintraub, W.S., Wenger, N.K., Jacobs, A.K., Smith, S.C.Jr., Anderson, J.L., Albert, N., Buller, C.E., Creager, M.A., Ettinger, S.M., Guyton, R.A., Halperin, J.L., Hochman, J.S., Kushner, F.G., Nishimura, R., Ohman, E.M., Page, R.L., Stevenson, W.G., Tarkington, L.G., Yancy, C.W., 2010. American College of Cardiology Foundation; American Heart Association. $2010 \mathrm{ACCF} / \mathrm{AHA}$ guideline for assessment of cardiovascular risk in asymptomatic adults. J. Am. Coll. Cardiol. 56, 50-103.

Haffner, S.M., Lehto, S., Rönnemaa, T., Pyörälä, K., Laakso, M., 1998. Mortality from coronary heart disease in subjects with type 2 diabetes and in nondiabetic subjects with and without prior myocardial infarction. N. Engl. J. Med. 339, 229-234.

Haider, A.W., Larson, M.G., Franklin, S.S., Levy, D., 2003. Framingham Heart Study. Systolic blood pressure, diastolic blood pressure, and pulse pressure as predictors of risk for congestive heart failure in the Framingham Heart Study. Ann. Intern. Med. 138, $10-16$.

Hawe, E., Talmud, P.J., Miller, G.J., Humphries, S.E., 2003. Second Northwick Park Heart Study. Family history is a coronary heart disease risk factor in the second northwick park heart study. Ann. Hum. Genet. 67, 97-106.

He, J., Vupputuri, S., Allen, K., Prerost, M.R., Hughes, J., Whelton, P.K., 1999. Passive smoking and the risk of coronary heart disease--a metaanalysis of epidemiologic studies. N. Engl. J. Med. 340, 920-926.

Hodis, H.N., Mack, W.J., LaBree, L., Selzer, R.H., Liu, C.R., Liu, C.H., Azen, S.P., 1998. The role of carotid arterial intima-media thickness in predicting clinical coronary events. Ann. Intern. Med. 128, 262-269.

Jaffer, F.A., O'Donnell, C.J., Larson, M.G., Chan, S.K., Kissinger, K.V., Kupka, M.J., Salton, C., Botnar, R.M., Levy, D., Manning, W.J., 2002. Age and sex distribution of subclinical aortic atherosclerosis: A magnetic resonance imaging examination of the Framingham Heart Study. Arterioscl. Throm. Vas. 22, 849-854.

Kannel, W.B., 1996. Blood pressure as a cardiovascular risk factor: Prevention and treatment. JAMA. 275, 1571-1576.

Kaplan, G.A., Keil, J.E., 1993. Socioeconomic factors and cardiovascular disease: A review of the literature. Circulation. 88, 1973-1998.

Khot, U.N., Khot, M.B., Bajzer, C.T., Sapp, S.K., Ohman, E.M., Brener, S.J., Ellis, S.G., Lincoff, A.M., Topol, E.J., 2003. Prevalence of conventional risk factors in patients with coronary heart disease. JAMA. 290, 898-904.

Kivimäki, M., Leino-Arjas, P., Luukkonen, R., Riihimäki, H., Vahtera, J., Kirjonen, J., 2002. Work stress and risk of cardiovascular mortality: Prospective cohort study of industrial employees. B.M.J. 325, 857.

Kraus, W.E., Houmard, J.A., Duscha, B.D., Knetzger, K.J., Wharton, M.B., McCartney, J.S., Bales, C.W., Henes, S., Samsa, G.P., Otvos, J.D., Kulkarni, K.R., Slentz, C.A., 2002. Effects of the amount and intensity of exercise on plasma lipoproteins. N. Engl. J. Med. 347, 14831492.

Knoops, K.T., de Groot, L.C., Kromhout, D., Perrin, A.E., Moreiras-Varela, O., Menotti, A., van Staveren, W.A., 2004. Mediterranean diet, lifestyle factors, and 10-year mortality in elderly European men and women: The HALE project. JAMA. 292, 1433-1439.

LaRosa, J.C., Grundy, S.M., Waters, D.D., Shear, C., Barter, P., Fruchart, J.C., Gotto, A.M., Greten, H., Kastelein, J.J., Shepherd, J., Wenger, N.K., 2005. Treating to new targets (T.N.T.) Investigators. Intensive lipid lowering with atorvastatin in patients with stable coronary disease. N. Engl. J. Med. 352, 1425-1435.

Lee, I.M., Sesso, H.D., Paffenbarger, R.S.Jr., 2000. Physical activity and coronary heart disease risk in men: Does the duration of exercise episodes predict risk? Circulation. 102, 981-986.

Lee, M., Saver, J.L., Towfighi, A., Chow, J., Ovbiagele, B., 2011. Efficacy of fibrates for cardiovascular risk reduction in persons with atherogenic dyslipidemia: A meta-analysis. Atherosclerosis. 217, 492-498.

Levy, D., Garrison, R.J., Savage, D.D., Kannel, W.B., Castelli, W.P., 1990. Prognostic implications of echocardiographically determined left ventricular mass in the Framingham Heart Study. N. Engl. J. Med. 322, 1561-1566. 
Lloyd-Jones, D.M., Nam, B.H., D'Agostino, R.B.Sr., Levy, D., Murabito, J.M., Wang, T.J., Wilson, P.W., O'Donnell, C.J., 2004. Parental cardiovascular disease as a risk factor for cardiovascular disease in middle-aged adults: A prospective study of parents and offspring. JAMA. 291, 2204-2211.

Lonn, E., Yusuf, S., Arnold, M.J., Sheridan, P., Pogue, J., Micks, M., McQueen, M.J., Probstfield, J., Fodor, G., Held, C., Genest, J.Jr., 2006. Heart Outcomes Prevention Evaluation (H.O.P.E.) 2 Investigators. Homocysteine lowering with folic acid and B vitamins in vascular disease. N. Engl. J. Med. 354, 1567-1577.

Lorenz, M.W., Markus, H.S., Bots, M.L., Rosvall, M., Sitzer, M., 2007. Prediction of clinical cardiovascular events with carotid intima-media thickness: A systematic review and meta-analysis. Circulation. 115, 459-467.

Maron, D.J., Ridker, P.M., Grundy, S.M., Pearson, T.A., 2008. Preventive strategies for coronary heart disease. In Hurst's the heart, Chapter 51, V. Fuster, R.A., Walsh, R.A., O'Rourke, P., Poole-Wilson, eds. McGraw-Hill, New York. 1203-1234.

Mathew, J., Sleight, P., Lonn, E., Johnstone, D., Pogue, J., Yi, Q., Bosch, J., Sussex, B., Probstfield, J., Yusuf, S., 2001. Heart Outcomes Prevention Evaluation (H.O.P.E.) Investigators. Reduction of cardiovascular risk by regression of electrocardiographic markers of left ventricular hypertrophy by the angiotensin-converting enzyme inhibitor ramipril. Circulation. 104, 1615-1621.

McGill, H.C.Jr., McMahan, C.A., Herderick, E.E., Zieske, A.W., Malcom, G.T., Tracy, R.E., Strong, J.P., 2002. Pathobiological Determinants of Atherosclerosis in Youth (P.D.A.Y.) Research Group. Obesity accelerates the progression of coronary atherosclerosis in young men. Circulation. 105, 2712-2718.

McMahan, C.A., Gidding, S.S., Viikari, J.S., Juonala, M., Kähönen, M., Hutri-Kähönen, N., Jokinen, E., Taittonen, L., Pietikäinen, M., McGill, H.C.Jr., Raitakari, O.T., 2007. Association of pathobiologic determinants of atherosclerosis in youth risk score and 15-year change in risk score with carotid artery intima-media thickness in young adults (from the Cardiovascular Risk in Young Finns Study). Am. J. Cardiol. 100, 1124-1129.

Menown, I.B., Mathew, T.P., Gracey, H.M., Nesbitt, G.S., Murray, P., Young, I.S., Adgey, A.A., 2003. Prediction of recurrent events by D-dimer and inflammatory markers in patients with normal cardiac troponin I study. Prediction of recurrent events by D-dimer and inflammatory markers in patients with normal cardiac troponin I (P.R.E.D.I.C.T.) study. Am. Heart J. 145, 986-992.

Mills, J.D., Mansfield, M.W., Grant, P.J., 2002. Tissue plasminogen activator, fibrin D-dimer, and insulin resistance in the relatives of patients with premature coronary artery disease. Arterioscl. Throm. Vas. 22, 704-709.

Nambi, V., Chambless, L., Folsom, A.R., He, M., Hu, Y., Mosley, T., Volcik, K., Boerwinkle, E., Ballantyne, C.M., 2010. Carotid intima-media thickness and presence or absence of plaque improves prediction of coronary heart disease risk: The A.R.I.C. (Atherosclerosis Risk In Communities) study. J. Am. Coll. Cardiol. 55, 1600-1607.

National Cholesterol Education Program (NCEP) Expert Panel on Detection, Evaluation, and Treatment of High Blood Cholesterol in Adults (Adult Treatment Panel III), 2002. Third report of the national cholesterol education program (NCEP) expert panel on detection, evaluation, and treatment of high blood cholesterol in adults (adult treatment panel III) final report. Circulation. 106, 3143-3421.

Ni, H., Coady, S., Rosamond, W., Folsom, A.R., Chambless, L., Russell, S.D., Sorlie, P.D., 2009. Trends from 1987 to 2004 in sudden death due to coronary heart disease: The atherosclerosis risk in communities (A.R.I.C.) study. Am. Heart J. 157, 46-52.

Pearson, T.A., Mensah, G.A., Alexander, R.W., Anderson, J.L., Cannon, R.O.3rd., Criqui, M., Fadl, Y.Y., Fortmann, S.P., Hong, Y., Myers, G.L., Rifai, N., Smith, S.C.Jr., Taubert, K., Tracy, R.P., Vinicor, F.; Centers for Disease Control and Prevention; American Heart Association, 2003. Markers of inflammation and cardiovascular disease: application to clinical and public health practice: A statement for healthcare professionals from the centers for disease control and prevention and the American heart association. Circulation. 107, 499-511.

Poirier, P., Giles, T.D., Bray, G.A., Hong, Y., Stern, J.S., Pi-Sunyer, F.X., Eckel, R.H., 2006. American heart association; obesity committee of the council on nutrition, physical activity, and metabolism. Obesity and cardiovascular disease: Pathophysiology, evaluation, and effect of weight loss: an update of the 1997 American heart association scientific statement on obesity and heart disease from the obesity committee of the council on nutrition, physical activity, and metabolism. Circulation. 113, 898-918.

Pradhan, A.D., LaCroix, A.Z., Langer, R.D., Trevisan, M., Lewis, C.E., Hsia, J.A., Oberman, A., Kotchen, J.M., Ridker, P.M., 2004. Tissue plasminogen activator antigen and D-dimer as markers for atherothrombotic risk among healthy postmenopausal women. Circulation. 110, 292-300.

Proietti, R., Mapelli, D., Volpe, B., Bartoletti, S., Sagone, A., Dal Bianco, L., Daliento, L., 2011. Mental stress and ischemic heart disease: Evolving awareness of a complex association. Future Cardiol. 7, 425-437.

Raggi, P., Callister, T.Q., Shaw, L.J., 2004. Progression of coronary artery calcium and risk of first myocardial infarction in patients receiving cholesterol-lowering therapy. Arterioscl. Throm. Vas. 24, 1272-1277.

Ridker, P.M., Cannon, C.P., Morrow, D., Rifai, N., Rose, L.M., McCabe, C.H., Pfeffer, M.A., Braunwald, E., 2005. Pravastatin or atorvastatin evaluation and infection therapy-thrombolysis in myocardial infarction 22 (PROVE IT-TIMI 22) investigators, C-reactive protein levels and outcomes after statin therapy. N. Engl. J. Med. 352, 20-28.

Ridker, P.M., Danielson, E., Fonseca, F.A., Genest, J., Gotto, A.M.Jr., Kastelein, J.J., Koenig, W., Libby, P., Lorenzatti, A.J., MacFadyen, J.G., Nordestgaard, B.G., Shepherd, J., Willerson, J.T., Glynn, R.J., JUPITER Study Group., 2008a. Rosuvastatin to prevent vascular events in men and women with elevated C-reactive protein. N. Engl. J. Med. 359, 2195-2207.

Ridker, P.M., Danielson, E., Fonseca, F.A., Genest, J., Gotto, A.M.Jr., Kastelein, J.J., Koenig, W., Libby, P., Lorenzatti, A.J., MacFadyen, J.G., Nordestgaard, B.G., Shepherd, J., Willerson, J.T., Glynn, R.J.; JUPITER Study Group, 2009. Reduction in C-reactive protein and LDL cholesterol and cardiovascular event rates after initiation of rosuvastatin: A prospective study of the JUPITER trial. Lancet. 373, 1175-1182.

Ridker, P.M., Libby, P., 2008. Risk factors for atherothrombotic disease. In Braunwald's heart disease, Chapter 39, P. Libby, R.O., Bonow, D.L., Mann, D.P., zipes, Eds. Saunders Elsevier, Philadelphia: pp. 1003-1026.

Ridker, P.M., Paynter, N.P., Rifai, N., Gaziano, J.M., Cook, N.R., 2008b. C-reactive protein and parental history improve global cardiovascular risk prediction: The Reynolds risk score for men. Circulation. 118, 2243-2251.

Ridker, P.M., Rifai, N., Pfeffer, M.A., Sacks, F., Braunwald, E., 1999. Long-term effects of pravastatin on plasma concentration of C-reactive protein. The cholesterol and recurrent events (C.A.R.E.) investigators. Circulation. 100, 230-235.

Ridker, P.M., Rifai, N., Rose, L., Buring, J.E., Cook, N.R., 2002. Comparison of C-reactive protein and low-density lipoprotein cholesterol levels in the prediction of first cardiovascular events. N. Engl. J. Med. 347, 1557-1565.

Rissanen, A.M., 1979. Familial aggregation of coronary heart disease in a high incidence area (North Karelia, Finland). Br. Heart J. 42, 294303.

Rosengren, A., Perk, J., Dallongeville, J., 2009. Prevention of cardiovascular disease. In ESC textbook of cardiovascular medicine, Chapter 12, 
A.J., Camm, T.F., Luscher, P.W., Serruys, eds. Oxford University Press, New York. 403-435.

Rothwell, P.M., Coull, A.J., Giles, M.F., Howard, S.C., Silver, L.E., Bull, L.M., Gutnikov, S.A., Edwards, P., Mant, D., Sackley, C.M., Farmer, A., Sandercock, P.A., Dennis, M.S., Warlow, C.P., Bamford, J.M., Anslow, P., Oxford Vascular Study, 2004. Change in stroke incidence, mortality, case-fatality, severity, and risk factors in Oxfordshire, UK from 1981 to 2004 (Oxford Vascular Study). Lancet. 363, $1925-1933$.

Rugulies, R., 2002. Depression as a predictor for coronary heart disease. A review and meta-analysis. Am. J. Prev. Med. 23, 51-61.

Sacks, F.M., Pfeffer, M.A., Moye, L.A., Rouleau, J.L., Rutherford, J.D., Cole, T.G., Brown, L., Warnica, J.W., Arnold, J.M., Wun, C.C., Davis, B.R., Braunwald, E., 1996. The effect of pravastatin on coronary events after myocardial infarction in patients with average cholesterol levels. Cholesterol and recurrent events trial investigators. N. Engl. J. Med. 335, 1001-1009.

Scanu, A.M., 1992. Lipoprotein(a). A genetic risk factor for premature coronary heart disease. JAMA. 267, 3326-3329.

Shah, T., Casas, J.P., Cooper, J.A., Tzoulaki, I., Sofat, R., McCormack, V., Smeeth, L., Deanfield, J.E., Lowe, G.D., Rumley, A., Fowkes, F.G., Humphries, S.E., Hingorani, A.D., 2009. Critical appraisal of CRP measurement for the prediction of coronary heart disease events: New data and systematic review of 31 prospective cohorts. Int. J. Epidemiol. 38, 217-231.

Simon, A., Megnien, J.L., Chironi, G., 2010. The value of carotid intima-media thickness for predicting cardiovascular risk. Arterioscl. Throm. Vas. 30, 182-185.

Solfrizzi, V., Panza, F., Colacicco, A.M., Capurso, C., D'Introno, A., Torres, F., Baldassarre, G., Capurso, A., 2002. Relation of lipoprotein(a) as coronary risk factor to type 2 diabetes mellitus and low-density lipoprotein cholesterol in patients $>$ or $=65$ years of age (The Italian Longitudinal Study on Aging). Am. J. Cardiol. 89, 825-829.

Tabit, C.E., Chung, W.B., Hamburg, N.M., Vita, J.A., 2010. Endothelial dysfunction in diabetes mellitus: Molecular mechanisms and clinical implications. Rev. Endocr. Metab. Dis. 11, 61-74.

Thom, T., Haase, N., Rosamond, W., Howard, V.J., Rumsfeld, J., Manolio, T., Zheng, Z.J., Flegal, K., O'Donnell, C., Kittner, S., Lloyd-Jones, D., Goff, D.C.Jr., Hong, Y., Adams, R., Friday, G., Furie, K., Gorelick, P., Kissela, B., Marler, J., Meigs, J., Roger, V., Sidney, S., Sorlie, P., Steinberger, J., Wasserthiel-Smoller, S., Wilson, M., Wolf, P.; American Heart Association Statistics Committee and Stroke Statistics Subcommittee, 2006. Heart disease and stroke statistics-2006 update: A report from the American heart association statistics committee and stroke statistics subcommittee. Circulation. 113, 85-151.

Thompson, P.D., Buchner, D., Pina, I.L., Balady, G.J., Williams, M.A., Marcus, B.H., Berra, K., Blair, S.N., Costa, F., Franklin, B., Fletcher, G.F., Gordon, N.F., Pate, R.R., Rodriguez, B.L., Yancey, A.K., Wenger, N.K., 2003. American heart association council on clinical cardiology subcommittee on exercise, rehabilitation, and prevention; american heart association council on nutrition, physical activity, and metabolism subcommittee on physical activity. Exercise and physical activity in the prevention and treatment of atherosclerotic cardiovascular disease: A statement from the council on clinical cardiology (Subcommittee on Exercise, Rehabilitation, and Prevention) and the council on nutrition, physical activity, and metabolism (Subcommittee on Physical Activity). Circulation. 107, 3109-3116.

Treasure, C.B., Klein, J.L., Weintraub, W.S., Talley, J.D., Stillabower, M.E., Kosinski, A.S., Zhang, J., Boccuzzi, S.J., Cedarholm, J.C., Alexander, R.W., 1995. Beneficial effects of cholesterol-lowering therapy on the coronary endothelium in patients with coronary artery disease. N. Engl. J. Med. 332, 481-487.

Turnbull, F., Blood Pressure Lowering Treatment Trialists' Collaboration, 2003. Effects of different blood-pressure-lowering regimens on major cardiovascular events: Results of prospectively-designed overviews of randomised trials. Lancet. 362, 1527-1535.

U.S. Department of Health and Human Services, 2004. The health consequences of smoking: A report of the surgeon general. Public health service centers for disease control and prevention, national center for chronic disease prevention and health promotion, office on smoking and health. Atlanta, GA: U.S.D.H.H.S.

Vasan, R.S., Larson, M.G., Leip, E.P., Evans, J.C., O'Donnell, C.J., Kannel, W.B., Levy, D., 2001. Impact of high-normal blood pressure on the risk of cardiovascular disease. N. Engl. J. Med. 345, 1291-1297.

Vaughan, D.E., 2005. PAI-1 and atherothrombosis. J. Thromb. Haemost. 3, 1879-1883.

Villines, T.C., Stanek, E.J., Devine, P.J., Turco, M., Miller, M., Weissman, N.J., Griffen, L., Taylor, A.J., 2010. The ARBITER 6-HALTS Trial (Arterial biology for the investigation of the treatment effects of reducing cholesterol 6-HDL and LDL treatment strategies in atherosclerosis): Final results and the impact of medication adherence, dose, and treatment duration. J. Am. Coll. Cardiol. 55, $2721-2726$.

Vucković, B., Derić, M., 2007. Lipoprotein(a): A link between thrombogenesis and atherogenesis. Med. Pregl. 60, 37-41.

Wang, X., Qin, X., Demirtas, H., Li, J., Mao, G., Huo, Y., Sun, N., Liu, L., Xu, X., 2007. Efficacy of folic acid supplementation in stroke prevention: A meta-analysis. Lancet. 369, 1876-1882.

Wilson, K.M., Lentz, S.R., 2005. Mechanisms of the atherogenic effects of elevated homocysteine in experimental models. Semin. Vasc. Med. $5,163-171$. 